\title{
A NOVA FORMA DE TRABALHO NO CENÁRIO PÓS COVID-19 NA INDÚSTRIA DE BEBIDAS. O QUE MUDOU?
}

\author{
THE NEW WAY OF WORKING IN THE POST COVID-19 SCENARIO IN THE BEVERAGE \\ INDUSTRY. WHAT HAS CHANGED?
}

\author{
Mayra Braga da Silva Lima ${ }^{*}$, Luana Maria Meireles Cunha ${ }^{2}$, \& Consuelo Lucia Sousa \\ de $_{\text {Lima }}^{3}$ \\ 123 Universidade Federal do Pará - UFPA. \\ 1* mayra.lima@itec.ufpa.br ${ }^{2}$ luana.cunha@itec.ufpa.br ${ }^{3}$ sousa@ufpa.br
}

\section{ARTIGO INFO.}

\section{Recebido em: 23.10.2021}

Aprovado em: 21.12.2021

Disponibilizado em: 02.02.2022

Palavras-Chave:

COVID-19; Pandemia; Indústria de Bebidas; Segurança.

KEYWORDS:

COVID-19; Pandemic; Beverage Industry; Security.

*Autor Correspondente: Lima, M. B., da S.

\section{RESUMO}

A pandemia da COVID-19 se propagou de maneira repentina por todo o mundo, alterando a realidade de toda uma sociedade, a qual precisou se adaptar a este novo cenário. As indústrias de alimentos foram bastante afetadas, e para manter seu funcionamento, precisaram buscar formas para se manter ativas, fornecendo um ambiente de trabalho ainda mais seguro para seus colaboradores. O objetivo deste estudo foi mostrar as mudanças ocorridas em uma indústria de bebidas durante a pandemia da COVID19. Para isto, foi realizado um levantamento de dados na indústria em questão, com a aplicação de um checklist baseado no Protocolo Sanitário Geral do Decreto $\mathrm{n}^{\circ} 800$, de 31 de maio de 2020, pelos setores da fábrica além de um questionário para os colaboradores, para evidenciar as mudanças ocorridas no dia a dia da empresa. Após este levantamento, foram identificadas mudanças estruturais e de conduta, como o distanciamento social, e também a implementação dos Diálogos Diários de Segurança (DDS) com temáticas relacionadas à prevenção contra a COVID-19. Após a aplicação do checklist, verificouse que a indústria em questão conseguiu atingir cerca de $94 \%$ de conformidades do Decreto $\mathrm{n}^{\circ} 800$, de 31 de maio de 2020. Portanto, com a instalação dessas medidas de prevenção, e os resultados obtidos por meio do checklist, foi evidenciado que a indústria de bebidas conseguiu fornecer um ambiente seguro para os seus colaboradores no contexto da pandemia da COVID-19.

\begin{abstract}
The COVID-19 pandemic spread suddenly throughout the world, changing the reality of an entire society, which had to adapt to this new scenario. The food industries were affected, and to keep their functioning a lot, they needed to look for ways to remain active, providing an even safer working environment for their employees. The study aimed to show how changes occurred in a beverage industry during the COVID-19 pandemic. For this, a data survey was carried out in the industry in question, with an application of a checklist based on the General Health Protocol of Decree No. 800, of May 31, 2020, by the factory sectors, in addition to a questionnaire for employees, to highlight the changes that have taken place in the company's day-to-day activities. After this survey, changes and conduct were identified, such as social distancing, and also the implementation of the Daily Safety Dialogues (DDS) with themes related to prevention against COVID-19. After applying the checklist, it was verified that the industry in question managed to achieve about $94 \%$ of compliance with Decree No. 800, of May 31, 2020. Therefore, the installation of these prevention measures and the results obtained through the checklist evidenced that the beverage industry provides a safe environment for its employees in the context of the COVID-19 pandemic.
\end{abstract}




\section{INTRODUÇÃO}

Em dezembro de 2019 foi identificado o primeiro caso registrado de Corona Virus Disease (COVID-19) em Wuhan, na China. Caracterizada como uma doença infectocontagiosa causada pelo coronavírus da síndrome respiratória aguda grave 2 (SARS-CoV-2), do inglês Severe Acute Respiratory Syndrome-Associated Coronavirus 2 (Brito, Braga, Cunha, Palácio, \& Takenami, 2020). A velocidade e intensidade da contaminação populacional pelo vírus levou a Organização Mundial da Saúde (OMS) a classificar a doença como pandemia em 11 de março de 2020. No Brasil, desde o registro do primeiro caso, assim como no restante do mundo, o vírus também tem se espalhado rapidamente por todos os Estados brasileiros (Porsse, Sousa, Carvalho, \& Vale, 2020).

Atualmente, ainda se faz necessário que o enfoque com relação à COVID-19 seja na epidemiologia, causas, manifestações clínicas e diagnoses, prevenção e controle da doença. No entanto, a preocupação com os efeitos na economia mundial já é alta, depois do longo período de lockdown e distanciamento social, impostos pelos Governos (Federal, Estadual e Municipal) a partir de orientações de cientistas e especialistas de saúde, como a principal alternativa de evitar a rápida transmissão da doença e o elevado número de mortes, visto que as vacinas estavam em período de desenvolvimento. $\mathrm{O}$ isolamento implicou a suspensão de grande número de atividades econômicas, causando desemprego particularmente no comércio e no setor de serviços.

A Organização Internacional do Trabalho (ILO, 2020) antecipou que pelo menos 200 milhões de trabalhadores poderiam perder seus empregos e segundo Kelly (2020) aproximadamente 22 milhões de pessoas perderam seus empregos no início de abril nos EUA, no Brasil, segundo o Instituto Brasileiro de Geografia e Estatística (IBGE) o número de pessoas desempregadas chegou a 14,1 milhões no trimestre encerrado em outubro (IBGE, 2020). O cenário global de crise e desaceleração da economia causou efeitos sobre os bens e serviços produzidos no Brasil. As projeções momentâneas do Banco Mundial indicaram uma queda de $8 \%$ no PIB brasileiro em 2020 (World Bank, 2020).

As estimativas do PIB divulgadas pelo IBGE em setembro de 2020 apontaram uma queda de 5,9\% no primeiro semestre em relação ao mesmo período de 2019 (IBGE, 2020). Apesar das estimativas pessimistas e do cenário atual, em 2020, a queda no PIB brasileiro foi de 4,1\%, cerca de $2 \%$ menos que o estimado para este período (Viana, 2021).

As legislações brasileira, vigentes, referentes às medidas para enfrentamento da emergência de saúde pública decorrente do coronavírus (Brasil, 2020a, 2020b, 2020c) determinam dentre os serviços considerados essenciais, e que não podem ser paralisados por medidas como a quarentena, as atividades como assistência à saúde, assistência social, de segurança pública e privada, de telecomunicações, a produção, distribuição, comercialização e entrega, realizadas presencialmente ou por meio do comércio eletrônico, de alimentos e bebidas, assim como a inspeção de alimentos, produtos e derivados de origem animal e vegetal, dentre outras.

Para minimizar os efeitos da crise e evitar falências, setores de serviços essenciais para a população, como o de alimentos, precisaram se adaptar a essa nova realidade que foi imposta pela pandemia. Muitos aderiram ao serviço de delivery, pagamento via aplicativo, home office, o que foi útil para microempresas, porém, para a realidade de pequenas e médias empresas, 

indústria de bebidas. O que mudou? Brazilian Journal of Production Engineering, 8(1), 33-48.

como algumas indústrias de alimentos, essas medidas não foram suficientes para mantê-las em pleno funcionamento, já que dependem de uma quantidade mínima de funcionários presentes fisicamente no setor de produção e, por conseguinte um fluxo de caixa para sua manutenção.

A indústria de bebidas se destaca no Brasil principalmente pela produção de refrigerantes e produção de cervejas. Esses ramos apresentam números robustos, respondendo por fração significativa do valor adicionado da indústria de transformação (Cervieri, Teixeira, Galinari, Rawet, \& Silveira, 2014). Mesmo não sendo um setor de trabalho intensivo, em termos absolutos o setor é responsável pela geração de dezenas de milhares de postos de trabalho. $\mathrm{O}$ setor possui ampla distribuição regional da produção, devido às características dos produtos, que têm a água como insumo básico (Viana, 2021).

No Brasil, entre as bebidas não alcoólicas, o refrigerante tem grande destaque e foi responsável por $68,1 \%$ dessas vendas (em volume) do País em 2020 (IBGE, 2021a). Os dados do IBGE referentes ao período 2016-2020 mostram uma retomada do crescimento da produção da indústria de bebidas não alcoólicas a partir de 2017, após dois anos de queda, em função da crise econômica vivenciada no biênio 2015-2016 (Viana, 2021).

A Associação Brasileira da Indústria de Alimentos (ABIA, 2020) identificou que a indústria brasileira de alimentos e bebidas registrou um crescimento de $6,7 \%$ em faturamento no ano de 2019 , em relação à 2018, atingindo $\mathrm{R} \$ 699,9$ bilhões. O setor responde por cerca de $23 \%$ dos empregos da indústria da transformação do país, registrando 1,6 milhão de empregos diretos. De acordo com Viana (2021), com o advento da pandemia da COVID-19, houve nova queda em 2020, de 0,7\% em relação a 2019, e apesar disso, a fabricação de refrigerantes correspondeu, em 2020, a 69,3\% do volume total produzido de bebidas não alcoólicas. Segundo as previsões da Emerging Markets Research data and News (EMIS, 2021), as projeções são estimulantes mediante o cenário atual, pois o crescimento médio anual das vendas (do inglês Compound Annual Growth Rate) (CAGR) de bebidas não alcoólicas no Brasil, bem como no restante do mundo, deverá ser de 1,2\% no período 2021-2025.

Visto a importância do setor de bebidas para o PIB do país o qual mesmo diante de uma desaceleração econômica, mantém crescimento, e com a necessidade de manter a produção em meio a pandemia da COVID-19, proporcionando um ambiente ainda mais seguro para os colaboradores, as empresas precisaram se adequar seguindo as recomendações estipuladas pelo Ministério da Saúde sobre este cenário.

Os procedimentos, técnicas e regulamentações que visam garantir a qualidade e a segurança dos produtos do setor de alimentos no Brasil, também abrangem qualidade e segurança de trabalho, sendo eles os regulamentos técnicos do Ministérios da Saúde e da Agricultura que determinam a adoção das Boas Práticas de Fabricação (BPF), Procedimentos Padrões de Higiene Operacional (PPHO) e a implementação dos sistemas APPCC (Análise de Perigos e Pontos Críticos de Controle) ou HACCP (Hazard Analysis and Critical Control Points), indicados pelo Codex Alimentarius (Rotondaro, Cristofoletti \& Torres, 2000).

A legislação brasileira para Boas Práticas de Fabricação em ambientes (Brasil, 2002), determina várias ações que visam diminuir a possibilidade de contaminação do alimento em produção. São regras de conduta pré-estabelecidas pela legislação, que também são essenciais na prevenção contra disseminação da COVID-19, as quais proíbem o uso de adornos pessoais 

indústria de bebidas. O que mudou? Brazilian Journal of Production Engineering, 8(1), 33-48.

(brincos, colares, pulseiras, alianças, relógios, entre outros) e exigem asseio pessoal (unhas curtas, limpas e sem esmalte, imberbe, banhos antes do início da jornada de trabalho).

Esses regulamentos também orientam que os uniformes utilizados pelos colaboradores (roupas, sapatos e EPI's) devem estar limpos, serem trocados diariamente e utilizados exclusivamente no ambiente fabril. Além disso, nas áreas de processamento de alimentos, é proibido, comer, fumar, tossir, cantar, assoviar ou outras condutas anti-higiênicas. Além do cuidado com a limpeza das mãos, banhos antes do início da jornada e a garantia de uniformes limpos a cada turno de trabalho podem diminuir o risco de transmissão da COVID-19 (Brasil, 2020a). Sousa (2020), evidencia que objetos do cotidiano (óculos, celular, entre outros) podem ser facilmente veículos de transmissão da COVID-19. Dessa forma, o objetivo do presente estudo é mostrar as mudanças ocorridas em uma indústria de bebidas localizada em Benevides no Estado do Pará durante a pandemia da COVID-19.

\section{METODOLOGIA DO ESTUDO}

Foi realizado um estudo de caso em uma indústria de bebidas localizada na Região Norte do Estado do Pará, na Cidade de Benevides, a qual possui fiscalização do Ministério da Agricultura, Pecuária e Abastecimento (MAPA). A unidade ocupa uma área total de 15.916,5 $\mathrm{m}^{2}$, possui 92 funcionários e é subdividida em setor administrativo, área de produção e controle de qualidade, almoxarifado (recebimento e armazenamento de matérias primas e insumos), estoque para armazenamento de produto acabado, estação de tratamento de água e de efluentes, manutenção, vestiários, dependências sanitárias e de higiene, e refeitório.

A indústria elabora refrigerantes e xaropes de marca própria e envasa para clientes da região, além de fornecer para supermercados, microempreendedores e cidades do Estado do Pará. Possuí implantado a sua realidade as Boas Práticas de Fabricação e o Programa 5S (5 Sensos SEIRE - senso de utilização, seleção, descarte. SEITON - senso de organização, arrumação. SEISO - senso de limpeza. SEIKETSU - senso de saúde, higiene e padronização. SHITSUKE senso de disciplina, autodisciplina).

\section{LEVANTAMENTO DE DADOS}

Foi realizado um estudo de caráter descritivo e qualitativo, o qual foi solicitado à direção da indústria em questão a autorização para realização da pesquisa, que foi realizada entre 29 de março a 06 de maio de 2021, período no qual a cidade de Benevides estava classificada como bandeiramento vermelho, que representa zona de alerta máximo com alto risco de contágio. Foi aplicado um checklist baseado no Protocolo Sanitário Geral, descritos no Decreto $\mathrm{n}^{\circ} 800$, de 31 de maio de 2020 do Governo do Estado do Pará (Pará, 2020). Também foi elaborado um questionário utilizando a ferramenta Google Forms, e aplicado com o objetivo de mapear a percepção dos colaboradores da Indústria de bebidas em relação a pandemia da COVID-19. Além de serem feitos registros fotográficos das modificações estruturais realizadas na empresa para melhor entendimento deste estudo.

\section{CHECKLIST}

No checklist foram abordados os itens relacionados ao Protocolo Sanitário Geral, descritos no Decreto $n^{\circ}$ 800, de 31 de maio de 2020 (Pará, 2020), que são: Proteção no contato social, higienização de ambiente e comunicação, porém apenas os subitens que tinham aplicabilidade à indústria de bebidas em questão, foram selecionados para a avaliação (Tabela1). 

indústria de bebidas. O que mudou? Brazilian Journal of Production Engineering, 8(1), 33-48.

$\underline{\text { Tabela 1. Itens e subitens do checklist aplicado a indústria de bebidas. }}$

\begin{tabular}{ccc}
\hline Itens avaliados & $\mathbf{N}^{\circ}$ de subitens & $\mathbf{N}^{\circ}$ de subitens avaliados \\
\hline Proteção no contato social & 62 & 38 \\
Higienização de ambientes & 15 & 8 \\
Comunicação & 7 & 6 \\
\hline Total & $\mathbf{8 4}$ & $\mathbf{5 2}$ \\
\hline
\end{tabular}

Fonte: Autores (2021)

Os subitens avaliados neste checklist foram separados em Sim (S), se a indústria atendesse ou Não $(\mathrm{N})$, caso a indústria não atendesse os requisitos estabelecidos pelo protocolo. Os dados obtidos neste checklist foram organizados em uma planilha no programa Microsoft Excel, e para cada item foi calculado o percentual de enquadramento (Equação 1) no decreto no período de estudo em que a cidade estava em bandeiramento vermelho.

$$
\% \text { Conformidade }=\left(\frac{\text { Quantidade de itens conformes }}{\text { Quantidade de itens totais }}\right) * 100 \quad \text { Eq.1 }
$$

\section{QUESTIONÁRIO}

O questionário "Mudanças pós pandemia na Indústria de Bebidas" (Quadro 1), composto por 11 perguntas, foi elaborado utilizando a ferramenta Google Forms e disponibilizado virtualmente para os 92 colaboradores da indústria em questão, abordando perguntas relacionadas as dificuldades enfrentadas por eles e as mudanças ocorridas durante este período de pandemia.

Quadro 1. Questionário sobre mudanças pós-pandemia na Indústria de bebidas aplicado aos colaboradores. Fonte: Autores (2021)

\section{Mudanças pós pandemia na Indústria de Bebidas}

Este questionário deve ser preenchido de acordo com as suas percepções com relação as mudanças no seu ambiente de trabalho no período pós pandemia da COVID-19, sejam estruturais ou comportamentais.

1- Em qual setor você trabalha?

a. Administrativo (RH, Compras, Comercial)

b. Asseguração da qualidade (Laboratório, xaroparia, ETA/ETE)

c. Serviços Gerais (Limpeza ou refeitório)

d. Produção (PCP, Sopro, Almoxarifado, Produção, Expedição, Manutenção)
2- Qual sua faixa etária?
a) 18 a 29 anos
b) 30 a 49 anos
c) 50 a 64 anos

3- Sexo:

a) Masculino

b) Feminino

c) Prefiro não dizer

4- Você faz parte do grupo de risco da pandemia da COVID-19?

5- Você sentiu dificuldades no início da pandemia?

a) $\mathrm{Sim}$

b) Não

6- Se sim, diga quais foram as principais dificuldades enfrentadas. Resposta:

7- Você percebeu alguma mudança na empresa nesse período de pandemia da COVID-19? a) Sim b) Não

\section{Sobre as mudanças}

8- Com relação as mudanças estruturais, quais delas foram percebidas por você no seu local de trabalho? Pode marcar mais de uma alternativa.
a. Placas inf
do álcool gel)
b. Bancos ao ar livre para o descanso
c. Alternativas de higienização de fácil acesso (água e sabão e/ou álcool em gel)
d. Acesso controlado de pessoas
e. Diálogos sobre medidas preventivas (Palestras, DDS)
f. Marcação no chão e bancos para indicar o distanciamento adequado
g. Isolamento dos bebedouros de pressão de uso comum
9- Com relação as mudanças comportamentais, quais delas você pratica no seu local de trabalho? Pode marcar mais de uma
a. Uso de máscara
b. Higienização frequente e correta das mãos
c. Uso de álcool em gel
d. Distanciamento Social
e. Home office
10 - Após essas mudanças, você se sentiu mais seguro no seu ambiente de trabalho? $\quad$ a) Sim $\quad$ b) Não
11- Você considera importantes para a prevenção contra a propagação do vírus, as mudanças realizadas na empresa?
a) $\mathrm{Sim}$
b) Não
c) Talvez alternativa. 

indústria de bebidas. O que mudou? Brazilian Journal of Production Engineering, 8(1), 33-48.

O questionário foi subdividido em três partes, sendo a primeira um termo de consentimento livre e esclarecido, indicando o interesse do colaborador em participar ou não da pesquisa. A segunda parte do questionário teve como objetivo traçar o perfil do colaborador, para isso houveram perguntas de cunho pessoal (idade, sexo, setor em que trabalha), perguntas para evidenciar de que maneira o colaborador enfrentou o período inicial da pandemia, além da sua percepção sobre as mudanças realizadas na indústria no período em questão.

A terceira parte do questionário tratou justamente dessas mudanças ocorridas, tanto as estruturais, quanto as comportamentais, implementadas pela direção da indústria. Além de questionar quais delas foram adotadas pelos colaboradores, e se eles as consideravam importantes (se era obrigação ou visão) para a prevenção contra o vírus.

\section{RESULTADOS E DISCUSS ÃO}

No início da pandemia, com o fechamento de bares, restaurantes, balneários, clubes, devido o decreto estadual de lockdown, a indústria se encontrou em crise com seu estoque cheio e nenhuma saída, precisando adotar medidas como: redução do quadro de funcionários, redução da jornada de trabalho, antecipação de férias, home office, mantendo-se apenas com a receita dos meses anteriores. Apenas após a liberação do funcionamento das atividades comerciais, a indústria conseguiu se reestabelecer, retornando à produção, realocando a maioria dos colaboradores em suas funções, e com isto houve a necessidade de minimizar os riscos de transmissão do vírus garantindo a segurança de todos no local de trabalho.

\section{CHECKLIST}

Após a aplicação do checklist, foi verificado que a indústria em questão conseguiu atingir cerca de $94 \%$ de conformidades (Figura 1), mostrando ser um local seguro para os colaboradores no contexto da pandemia da COVID-19. Apenas $6 \%$ dos subitens avaliados não foram atendidos, sendo estes relacionados aos itens proteção no contato social e higienização de ambientes. Vale ressaltar que o bandeiramento, é muito dinâmico, variando de situações mais brandas, com risco mínimo (bandeira azul) a situações mais graves, de lockdown (bandeira preta).

Figura 1. Resultado do checklist por subitens avaliados.

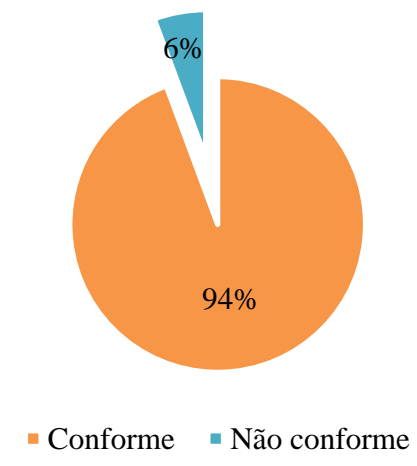

No item proteção no contato social, os subitens não atendidos pela indústria foram os relacionados a alimentação coletiva realizada no refeitório, e compartilhamento de objetos durante a alimentação. Devido ao corte de custos, e para evitar o consumo excessivo de descartáveis, para a refeição dos colaboradores, a indústria passou a adotar o uso de pratos de louça e talheres de inox, apesar de não ser o recomendado pelo decreto. Antes e após o uso 

indústria de bebidas. O que mudou? Brazilian Journal of Production Engineering, 8(1), 33-48.

destes objetos, eles eram higienizados de maneira adequada, e separados para serem utilizados novamente na próxima refeição. Há também o compartilhamento de saleiros, farinheiras, entre outros utensílios durante as refeições, em desacordo com o estabelecido pelo decreto.

Ainda, no quesito de alimentação, no subitem que estabelece que os bebedouros de pressão de uso comum devem ser lacrados, este não era cumprido pela indústria, porém após a realização desta avaliação, devido haver a necessidade de todos os bebedouros de acionamento por pressão de uso comum serem substituídos por torneiras, foi realizada a troca dos mesmos, evitando, dessa forma, o contato direto dos colaboradores ao beberem água (Figura 2).

Figura 2. Bebedouros de acionamento de pressão substituídos por torneiras.

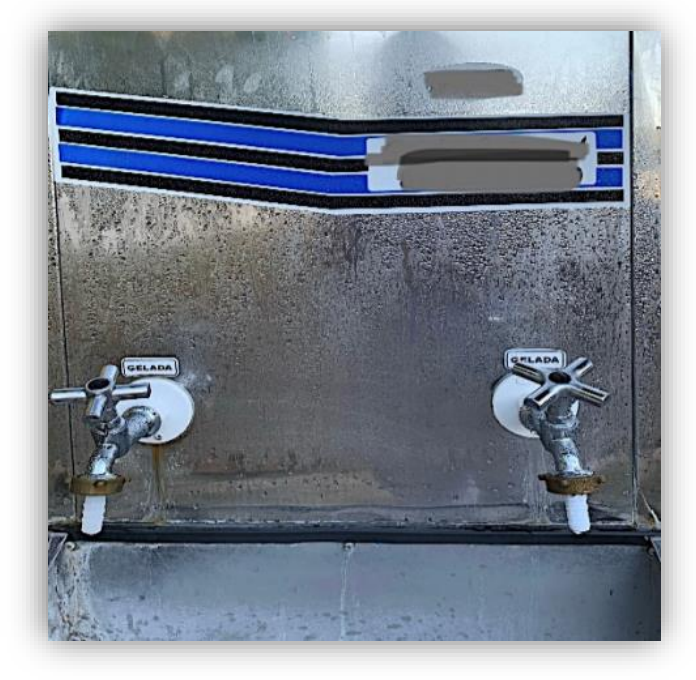

Fonte: Autores (2021)

No item, higienização de ambientes, o subitem não cumprido pela indústria foi relacionado ao uso do ponto biométrico, o qual de acordo com o decreto estadual deve ser evitado, porém, a indústria não deixou de fazer uso regular desta forma de registro, mas como alternativa, instalou um dispenser com álcool gel, acionado por pedal, para os colaboradores higienizarem as mãos antes e após a utilização do relógio de ponto biométrico digital.

Um dos subitens trazidos pelo checklist é relacionado ao uso obrigatório e correto máscaras, o qual também é amparado pela a lei $\mathrm{n}^{\circ} 14.019 / 2020$ (Brasil, 2020) que dispõe sobre a obrigatoriedade do uso de máscaras de proteção individual para circulação em espaços públicos e privados, sendo esta uma medida adotada por todos os colaboradores da indústria.

O uso de máscaras tem se mostrado uma ferramenta eficiente a prevenção do coronavírus, além do que, diversos estudos (Cheng et al., 2020; French National Academy Of Medicine, 2020; Ho, Lin, Weng, \& Chuang, 2020; Phan \& Ching, 2020; Zeng, Zewen, Sherrianne, Dinggiang, \& Hongwei, 2020) destacam a importância desse EPI como ferramenta para redução da transmissão do vírus. A Agência Nacional de Vigilância Sanitária (Anvisa) (Brasil, 2020b) recomenda o uso de máscaras de proteção facial, descartáveis ou reutilizáveis, mesmo para os trabalhadores envolvidos em atividades que não demandem a utilização de EPI de proteção respiratória específicos, e destaca que elas podem contribuir para diminuir o risco de transmissão da COVID-19, podendo ser utilizadas visando evitar a contaminação de alimentos prontos para o consumo e também para proteger a saúde do trabalhador. 

indústria de bebidas. O que mudou? Brazilian Journal of Production Engineering, 8(1), 33-48.

Em todos os setores fabris, foram fixados avisos sobre a obrigatoriedade do uso de máscaras, importância da lavagem correta das mãos (Figura 3a), formas de prevenção contra o coronavírus (Figura 3b), e também dispenser para álcool em gel acionados por pedal na recepção e na entrada do setor de produção (Figura 3c), visto que a higienização das mãos e punhos é uma das medidas mais importantes para a prevenção da COVID-19.

Segundo Sousa (2020), as áreas de produção devem ter instalações adequadas e convenientes para lavagem e secagem das mãos sempre que a natureza das operações assim o exija. Deve-se dispor de água fria ou quente e de elementos adequados (sabonete líquido, detergente, desinfetante, entre outros) para higienização das mãos. Deve haver também um meio higiênico adequado para secagem das mãos, não sendo permitido o uso de toalhas de tecido. No caso de se usar toalhas de papel, deve haver um controle de qualidade higiênico-sanitária e dispositivos de distribuição e lixeiras acionadas por pedal, requisitos estes, atendidos pela indústria em questão.

Figura 3. Formas de prevenção contra a COVID-19.

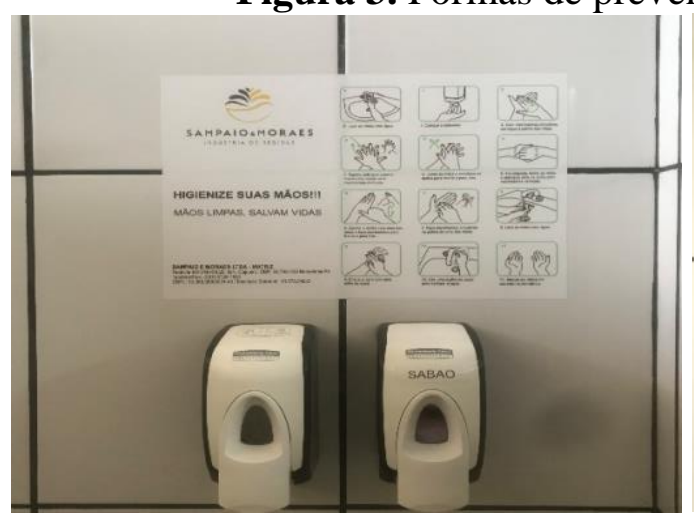

a

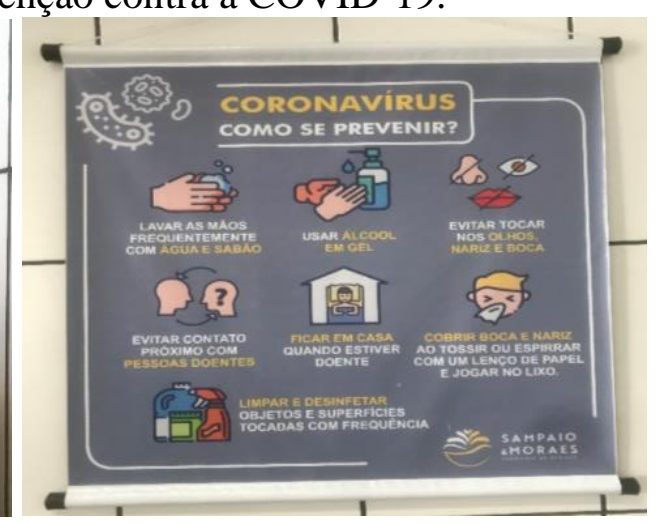

b

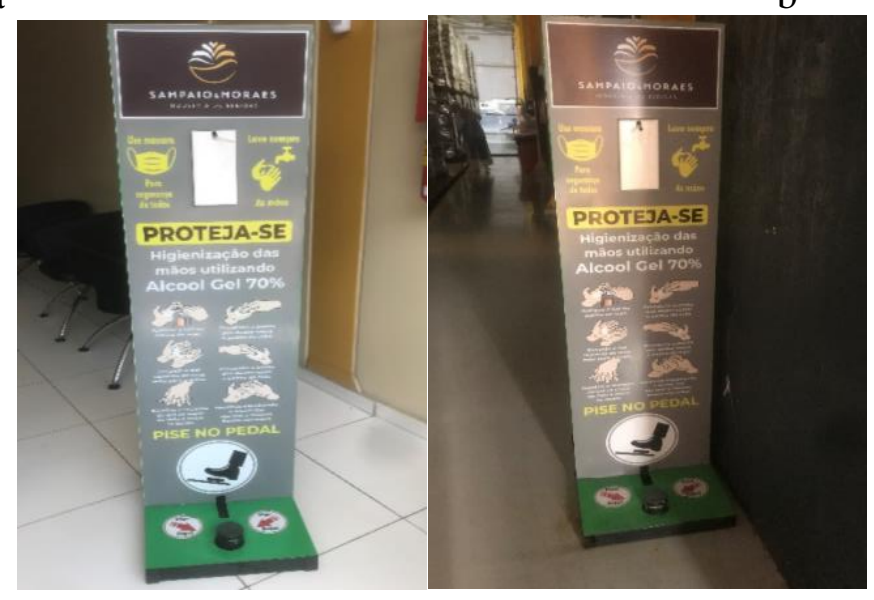

$\mathrm{C}$

Fonte: Autores (2021)

Outro aliado na prevenção contra a COVID-19 é o distanciamento social. Isso ocorre devido a minimização do contato entre indivíduos potencialmente infectados e indivíduos saudáveis. Todos os negócios do ramo alimentício devem seguir as orientações de distanciamento social o máximo possível (Sousa, 2020). A recomendação da OMS (WHO, 2020) é que seja mantida uma distância mínima de 1 metro entre funcionários. Essa é também a distância mínima recomendada pela ANVISA (Brasil, 2020a).

\section{@ $\odot \odot \odot$}



indústria de bebidas. O que mudou? Brazilian Journal of Production Engineering, 8(1), 33-48.

No refeitório da empresa, a refeição passou a ser servida por serventes e não mais pelos próprios funcionários, foram limitados apenas dois colaboradores por mesa ao invés de quatro, para evitar aglomeração. A sala de descanso que era um local fechado, foi substituída por bancos demarcados posicionados ao redor da fábrica (Figura 4a). Locais de alto fluxo de pessoas foram demarcados e com acesso limitado (Figura 4b).

Figura 4. Adaptações estruturais para prevenção contra a COVID-19.
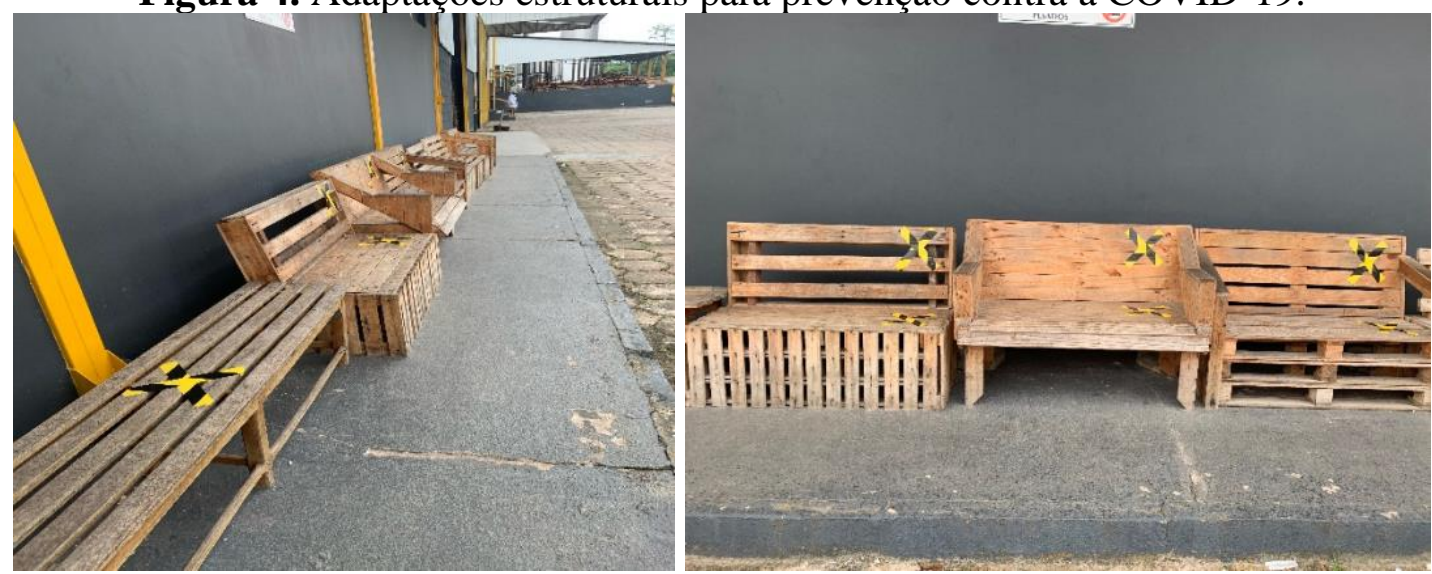

a

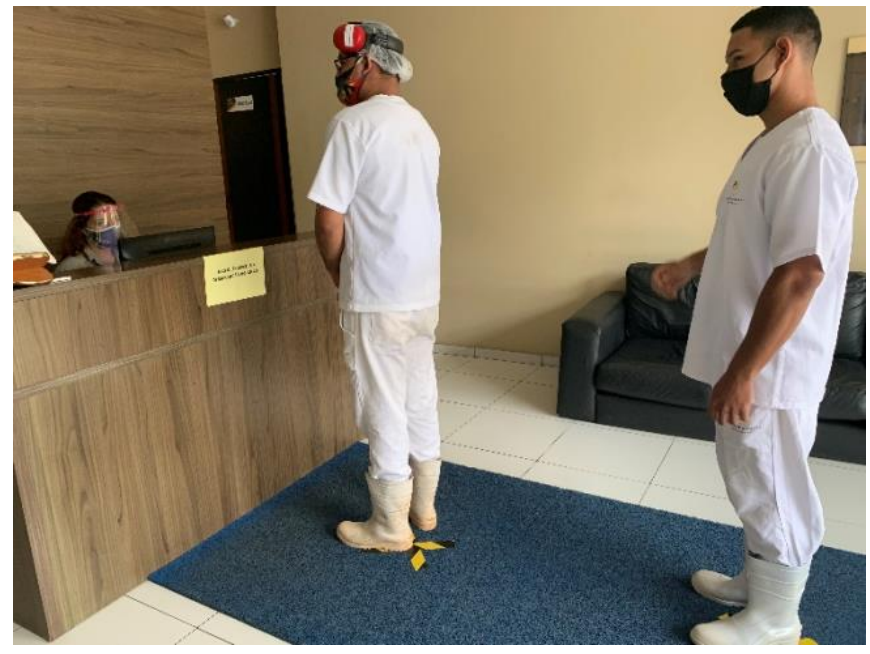

b

Fonte: Autores (2021)

A higienização de ambientes sempre foi um quesito presente na indústria, até mesmo por ser um ponto necessário para se atender a $\operatorname{RDC~n}^{\circ}$ 275/2002 (Brasil, 2002), sendo mais intensificada durante o período da pandemia da COVID-19. Cada colaborador responsável pela limpeza geral dos ambientes foi instruído a reforçar esse processo, utilizando os EPI's adequados para isto, bem como os colaboradores de cada setor, ao iniciarem e finalizarem seu turno realizavam a higienização da sua área, minimizando a possibilidade de contaminação pelo vírus.

A comunicação e propagação de informações verídicas é de extrema importância e a empresa é a principal responsável por orientar seus colaboradores. Segundo a ANVISA as empresas devem fornecer orientações aos trabalhadores para o uso, descarte e substituição da máscara

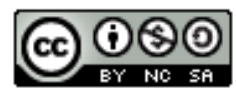


facial, higienização das mãos antes e após o seu uso, e, inclusive, limitações de sua proteção contra a COVID-19 (Brasil, 2020b). Dessa forma, além das mudanças estruturais na empresa, também foram acrescentados no dia a dia a realização de Diálogos Diários de Segurança (DDS), os quais são essenciais pois trazem temas relacionados a segurança do trabalho, e neste sentido, aborda sobre os cuidados e medidas preventivas contra a COVID-19 no ambiente de trabalho.

Para os novos funcionários que realizaram integração, etapa que consiste em aplicação de informações e treinamento intensivo ao novo colaborador, no momento que ingressam na empresa, durante os treinamentos é reforçado a importância do uso de máscaras, distanciamento social e lavagem adequada das mãos, sendo este último um quesito básico das Boas Práticas de Fabricação.

\section{QUESTIONÁRIO}

O questionário foi desenvolvido e aplicado com a intenção de entender de que forma as mudanças realizadas na empresa foram percebidas por cada colaborador e se elas estão sendo aplicadas no seu dia a dia. O questionário disponibilizado para os 92 colaboradores, recebeu 43 respostas, sendo subdivido em três partes, o termo de consentimento livre e esclarecido, "perfil do colaborador" e "sobre as mudanças" (Tabela 2).

Tabela 2. Perfil do colaborador.

Setor

\begin{tabular}{|c|c|}
\hline Setor & Respostas obtidas \\
\hline Asseguração da Qualidade (Laboratório, xaroparia, ETA/ETE) & 15 \\
\hline Produção (PCP, Sopro, Almoxarifado, Produção, Expedição, Manutenção) & 19 \\
\hline Administrativo (RH, Compras, Comercial) & 08 \\
\hline Serviços gerais (Limpeza ou refeitório) & 01 \\
\hline \multicolumn{2}{|l|}{ Faixa etária } \\
\hline 18 a 29 anos & 32 \\
\hline 30 a 49 anos & 08 \\
\hline 50 a 64 anos & 03 \\
\hline \multicolumn{2}{|l|}{ Sexo } \\
\hline Feminino & 29 \\
\hline Masculino & 14 \\
\hline
\end{tabular}

Fonte: Autores (2021)

A Tabela 2 mostra o perfil dos colaboradores que participaram da pesquisa, dentre eles $93,3 \%$ afirmaram que não fazem parte do grupo de risco da pandemia - pessoas idosas e com outras condições de saúde como pressão alta, problemas cardíacos e do pulmão, diabetes ou câncer (WHO, 2020) - mas que apesar disso, 65,1\% dos entrevistados afirmaram ter tido alguma dificuldade no início da pandemia. As principais dificuldades relatadas foram: dificuldades financeiras, adaptação ao uso de máscaras e as medidas restritivas impostas pelo governo, adequação da empresa às novas exigências governamentais, restrição do contato com os familiares e medo de perder o emprego devido à baixa demanda do mercado consumidor.

O sentimento de medo pelo provável desemprego era algo muito natural nesse período inicial da pandemia. De acordo com Silva e Silva (2020), observou-se que a confiança do empresário industrial e da economia começaram a cair a partir de março de 2020. Os dados sobre o emprego ainda são incipientes para uma análise mais profunda, apesar de indicarem uma redução da população ocupada e ampliação da população desocupada (Ministério da Economia, 2020).

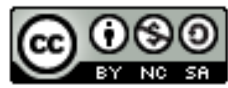



indústria de bebidas. O que mudou? Brazilian Journal of Production Engineering, 8(1), 33-48.

Devido isto para amenizar os impactos da redução da atividade econômica na pandemia, foi necessário a adoção de algumas medidas como, home office e horários flexíveis (turnos alternados), distanciamento social, turnos de trabalho escalonados, prestação de serviços remotos e outras medidas de redução de exposição são medidas de prevenção nãofarmacológicas cientificamente comprovadas (Sousa, 2020). Também é possível classificar os locais de trabalho em áreas de risco médio, risco alto ou risco muito alto, de acordo com a exposição de trabalhadores (Osha, 2020).

No tópico do questionário (Quadro 1) "Sobre as mudanças" foram realizadas quatro perguntas, sendo a primeira sobre quais mudanças foram percebidas pelos colaboradores no dia a dia da indústria. A presença das placas informativas foi a mudança mais percebida dentro da empresa (97,7\%), seguida pelas alternativas de higienização (76,7\%), DDS e as marcações no chão e bancos (ambos com 74,4\%), bancos para descanso ao ar livre $(69,8 \%)$, acesso controlado de pessoas $(48,8 \%)$ e isolamento dos bebedouros de pressão $(34,9 \%)$ (Figura 5).

Figura 5. Respostas referentes as mudanças percebidas pelos colaboradores na indústria.

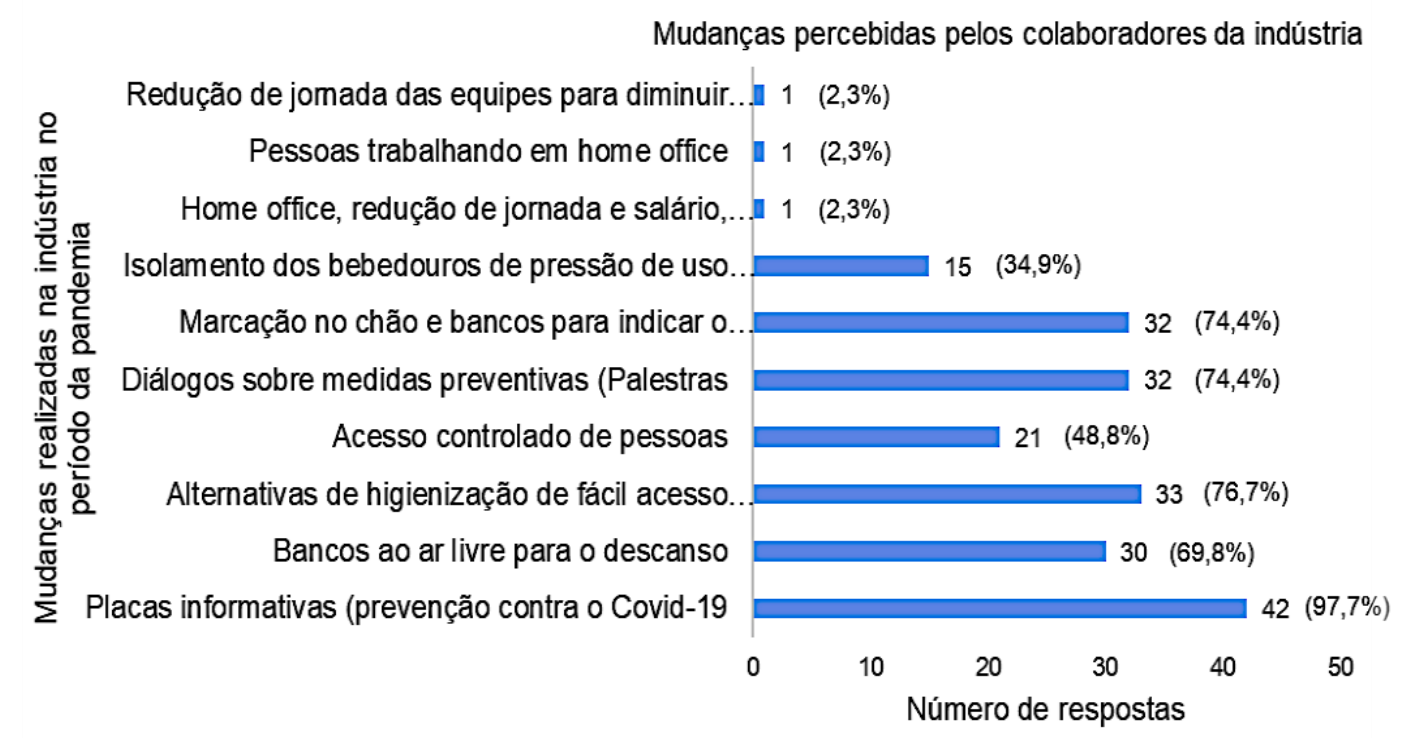

Fonte: Autores (2021)

A segunda pergunta teve o intuito de saber quais das medidas eram aplicadas pelos colaboradores, como pode ser visto na Figura 6. O uso de máscara é uma medida estritamente obrigatória, por conseguinte é a medida mais adotada pelos colaboradores da indústria $(97,7 \%)$, seguida pela higienização correta das mãos (87\%), uso do álcool em gel $(83,7 \%)$, distanciamento social (51,2\%), home office e orientações verbais (ambas com 2,3\%). Vale ressaltar, que as principais medidas adotadas pelos colaboradores são justamente aquelas evidenciadas pelas placas informativas sobre prevenção contra a COVID-19 fixadas pelos setores da indústria.

De acordo com a Portaria n 326 de 30 de julho de 1997 (Brasil, 1997), que traz o regulamento técnico sobre condições higiênico-sanitárias e de Boas Práticas de Fabricação para estabelecimentos produtores/industrializadores de alimentos, toda pessoa que trabalha em uma 

indústria de bebidas. O que mudou? Brazilian Journal of Production Engineering, 8(1), 33-48.

área de manipulação de alimentos deve, enquanto em serviço, lavar as mãos de maneira frequente e cuidadosa com um agente de limpeza autorizado e com água corrente potável.

Segundo Michelin, Lins e Falavigna (2020), se uma pessoa infectada com COVID-19 não utilizar a proteção necessária e houver disseminação de gotículas em superfície, é possível a ocorrência do contágio, principalmente se a pessoa que tocou essa superfície levar a mão à boca, ao nariz e aos olhos. Estudos evidenciam que o vírus possa sobreviver de horas a dias, logo é necessário sempre higienizar com água e sabão ou álcool $70 \%$ todas as superfícies, para evitar a transmissão, sabendo que as mãos podem ser um veículo de contaminação, além de ser um requisito das BPF's, um dos objetivos da higienização correta das mãos neste cenário atual é inviabilizar qualquer cepa do SARS-CoV-2 que possa estar presente nas mãos e punhos de manipuladores de alimentos, sendo assim a principal medida preventiva adotada pelos colaboradores (Figura 6).

Figura 6. Respostas referentes as medidas preventivas adotadas pelos colaboradores.

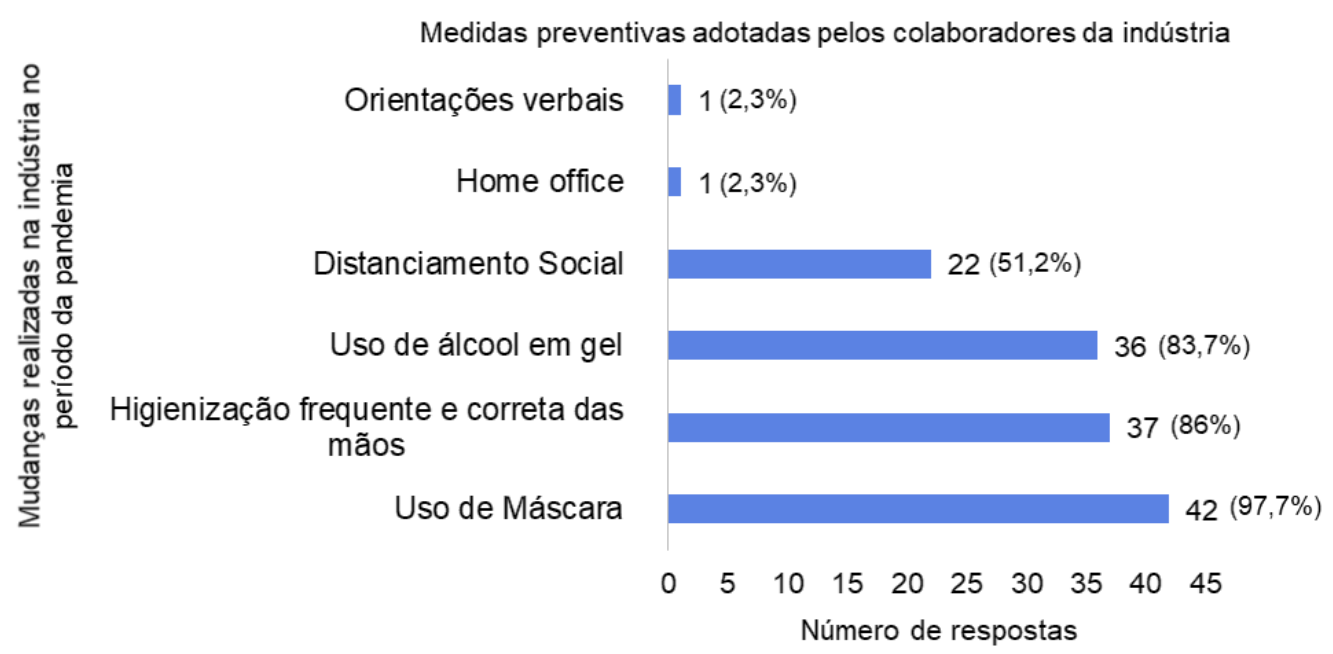

Fonte: Autores (2021)

O distanciamento social, é evidenciado melhor fora do setor de produção, durante o intervalo dos colaboradores, com o uso do bancos para descanso ao ar livre, ou caso aja a necessidade de se encaminharem a recepção, respeitando as demarcações no chão, pois muitas vezes no setor de produção se torna inviável essa medida, dessa forma a OMS (WHO, 2020) orienta que, em locais nos quais o ambiente de produção tornar difícil manter a distância mínima entre os colaboradores, os administradores considerem a implementação de medidas para a proteção dos empregados, como disponibilização de EPI's como, máscaras, toucas, luvas descartáveis e aventais limpos além de limitar do número de funcionários em determinadas áreas, principalmente as de comum convívio. Medidas as quais já são implantadas pela indústria em questão.

\section{CONCLUSÃO}

O trabalho foi desenvolvido com o intuito de mostrar as dificuldades enfrentadas e mudanças ocorridas em uma indústria de bebidas da região Norte, no período da pandemia da COVID-19. Em meio a tantas incertezas enfrentadas neste período, foi visto que apesar dos problemas iniciais, a indústria conseguiu se reerguer e encontrou formas de proporcionar um ambiente 

indústria de bebidas. O que mudou? Brazilian Journal of Production Engineering, 8(1), 33-48.

ainda mais seguro para seu funcionamento e saúde dos colaboradores, atingindo bons resultados, os quais foram evidenciados com a aplicação do checklist, com a implementação de regras de conduta mais rigorosas, obrigatoriedade do uso de máscaras e distanciamento social, por exemplo.

O questionário aplicado aos colaboradores evidenciou que a cultura de Boas Práticas de Fabricação implementadas na empresa facilitou a adaptação dos colaboradores a essa nova realidade de pandemia. As medidas preventivas adotadas para mitigar a possibilidade de transmissão do vírus, aparentemente simples, são eficientes e têm tido resultados positivos que perduram até hoje, em razão de que no quadro de funcionários não houve nenhum caso grave da doença, e consequentemente nenhum óbito causado pela COVID-19, comprovando a eficiência e comprometimento de todos os colaboradores, para a manutenção da segurança no dia a dia da empresa.

Vale destacar que apesar do presente estudo se limitar a um estudo de caso local, serve de parâmetro para outras pesquisas, podendo ser utilizado para estudos de caso múltiplos, comparando as mais diversas experiências ocorridas no contexto da pandemia da COVID-19. Além do que, embora a pandemia imponha a sociedade a uma realidade completamente atípica, ela também pôde colaborar com o aprimoramento e desenvolvimento de práticas essenciais para a permanência do funcionamento de maneira segura de inúmeros setores como a indústria de bebidas estudada durante este período,

\section{REFERÊNCIAS}

ABIA. (2020). Associação Brasileira da Indústria de Alimentos. Release: Indústria de Alimentos cresce 6,7\% em 2019. Recuperado em 30 de junho de 2021, de: https://www.abia.org.br/releases/industria-de-alimentos-cresce-67-em-2019

Brasil. (2002). Agência Nacional de Vigilância Sanitária. Resolução da Diretoria Colegiada ${ }^{\circ}$ 275, de 21 de outubro de 2002. Dispõe sobre o Regulamento Técnico de Procedimentos Operacionais Padronizados aplicados aos Estabelecimentos Produtores/Industrializadores de Alimentos e a Lista de Verificação das Boas Práticas de Fabricação em Estabelecimentos Produtores/Industrializadores de Alimentos. Recuperado de: http://bvsms.saude.gov.br/bvs/saudelegis/anvisa/2002/anexos/anexo_res0275_21_10_2002_re p.pdf. Acesso em: 27 jun. 2021.

Brasil. (2019). Instituto Brasileiro de Geografia e Estatística. Pesquisa de orçamentos familiares 2017-2018: primeiros resultados. Coordenação de Trabalho e Rendimento. Rio de Janeiro: IBGE, 2019. Recuperado em 12 de abril de 2020 de: https://biblioteca.ibge.gov.br/visualizacao/livros/liv101670.pdf.

Brasil. (2020a). Ministério da Saúde. Doença pelo Coronavírus 2019. COVID-19: Boletim epidemiológico, Brasília, n. 5, mar. 2020. Recuperado em 12 de abril de 2020 de: http://maismedicos.gov.br/images/PDF/2020_03_13_Boletim-Epidemiologico-05.pdf

Brasil. (2020b). Ministério da Saúde. Infecção pelo novo Coronavírus (2019-nCoV). COVID19: Boletim epidemiológico, Brasília, n. 1, jan. 2020. Recuperado em 12 de abril de 2020 de: https://www.saude.gov.br/images/pdf/2020/fevereiro/04/Boletim-epidemiologico-SVS$\underline{04 f e v 20 . p d f}$

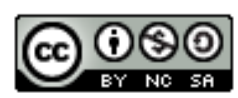


Citação (APA): Lima, M. B. da S., Cunha, L. M. M., \& Lima, C. L. S., de. (2022). A nova forma de trabalho no cenário pós covid-19 na indústria de bebidas. O que mudou? Brazilian Journal of Production Engineering, 8(1), 33-48.

Brasil. (2020c). Ministério da Saúde. Portaria MS No 188. Declara Emergência em Saúde Pública de importância Nacional (ESPIN) em decorrência da Infecção humana pelo novo Coronavírus (2019-nCoV). Diário Oficial da União, Brasília, n. 24, fev. 2020. Recuperado em 12 de abril de 2020 de: http://www.in.gov.br/en/web/dou/-/portaria-n-188-de-3-de-fevereirode-2020-241408388

Brasil. (1997). Ministério Da Saúde. Portaria SVS/MS nº 326, de 30 de julho de 1997. Aprova o Regulamento Técnico Condições Higiênicos-Sanitárias e de Boas Práticas de Fabricação para Estabelecimentos Produtores/Industrializadores de Alimentos. Recuperado em 27 de junho de 2020 de: http://portal.anvisa.gov.br/documents/33916/388704/Portaria\%2BSVSMS\%2BN.\%2B326\%2Bde\%2B30\%2Bde\%2BJulho\%2Bde\%2B1997.pdf/87a1ab03-06504e67-9f31-59d8be3de167.

Brasil. (2021). Ministério da Agricultura, Pecuária e Abastecimento. Portaria MAPA n ${ }^{\circ}$ 123, de 13 de maio de 2021. Estabelece os padrões de identidade e qualidade para bebida composta, chá, refresco, refrigerante, soda e, quando couber, os respectivos preparados sólidos e líquidos. Diário Oficial da União, Brasília, ed. 90, seção 1, p. 5, 14 de mai. 2021. Recuperado em 13 de julho de 2021 de: https://www.in.gov.br/en/web/dou/-/portaria-mapa-n-123-de-13de-maio-de-2021-319830736.

Brasil. (2020). Governo do Estado do Pará. Lei no 14.019, de 2 de julho de 2020. Diário Oficial da União. Edição: 172-A. Seção: 1. Recuperado em 28 de dezembro de 2020 de: https://www.in.gov.br/en/web/dou/-/lei-n-14.019-de-2-de-julho-de-2020-276227423.

Brito, S. B. P., Braga, I. O., Cunha, C. C., Palácio, M. A. V., \& Takenami, I. (2020). Pandemia da COVID-19: o maior desafio do século XXI. Vigilância Sanitária em Debate, vol. 8, n. 2, p. 54-63 INCQS-FIOCRUZ. Recuperado em 11 de outubro de 2020 de: https://www.redalyc.org/articulo.oa?id=570567430007.

Cervieri, O. Jr., Teixeira, J. R. Jr., Galinari, R., Rawet, E. L., \& Silveira, C. T. J. da. (2014). O setor de bebidas no Brasil. BNDES Setorial, Rio de Janeiro, n. 40, 93-129. Recuperado de: http://web.bndes.gov.br/bib/jspui/handle/1408/3462

Cheng, V. C. C., Wong, S. C., Chuang, V. W. M., So, Y. C., Chen, J. H., Sridhar, S., Wang, K. K., Chan, J. F. W., Hung, I. F. N., Ho, P. L., \& Yuen, Y. K. (2020). The role of communitywide wearing of face mask for control of coronavirus disease (Covid-19) epidemic due to SARS-CoV-2. Journal Of Infection, p. 1-8. DOI: 10.1016/j.jinf.2020.04.024. Recuperado em 27 de junho de 2021 de: https://www.sciencedirect.com/science/article/pii/S0163445320 $\underline{302358}$.

EMIS. (2021). Emerging Markets Research data and News. Brazil Food and Beverage Sector. Recuperado em 13 de outubro de 2021 de: https://www.emis.com.

French National Academy Of Medicine. (2020). Masks and COVID-19. Coronavirus: Opinion Of The French National Academy Of Medicine. Bulletin de L'académie Nationale de Médecine, p. 1-4. DOI: 10.1016/j.banm.2020.05.002. Recuperado em 27 de junho de 2021 de: https://www.sciencedirect.com/science/article/pii/S0001407920 302168.

Ho, K. F., Lin, L. Y., Weng, S. P., \& Chuang, K. J. (2020). Medical mask versus cotton mask for preventing respiratory droplet transmission in micro environments. Science of The Total Environment, v. 735, p. 1-4. DOI: 10.1016/j.scitotenv.2020.139510. Recuperado em 27 de junho de 2021 de: https://www.sciencedirect.com/science/article/pii/S0048969720 330278.

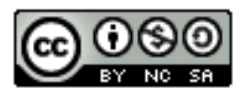



indústria de bebidas. O que mudou? Brazilian Journal of Production Engineering, 8(1), 33-48.

IBGE. (2020). Instituto Brasileiro de Geografia e Estatística. Pesquisa Nacional por Amostra de Domicílios (PNAD) Covid-19. Recuperado em 21 de novembro de 2020, de: https://covid19.ibge. gov.br/pnad-covid/trabalho.php

IBGE. (2020). Instituto Brasileiro de Geografia e Estatística. . Pesquisa Nacional por Amostra de Domicílios (PNAD) Covid-19. Estatísticas Sociais. Recuperado em 29 de dezembro de 2021, de: $\quad$ https://agenciadenoticias.ibge.gov.br/agencia-noticias/2012-agencia-denoticias/noticias/29782-numero-de-desempregados-chega-a-14-1-milhoes-no-trimestre-ateoutubro

IBGE. (2021). Instituto Brasileiro de Geografia E Estatística. Pesquisa industrial anual - PIA. Recuperado em 13 de outubro de 2021 de: https://sidra.ibge.gov.br/tabela/5807.

ILO. (2020). International Labour Organization. Almost 25 million jobs could be lost worldwide as a result of COVID-19, says ILO. Recuperado em 21 de novembro de 2020 de: https://www.ilo.org/global/about-the-ilo/newsroom/news/WCMS 738742/lang-en/index.htm

Kelly, J. (2020). The U.S. Now has 22 million people out of work, as 5.2 million more americans filed for unemployment last week. Recuperado em 21 de novembro de 2020 de: https://www.forbes.com/sites/jackkelly/2020/04/16/the-us-now-has-22-million-people-out-ofwork-as-52-million-more-americans-filed-for-unemployment-last-week/?sh=543c27411d53

Michelin, L., Lins, R. S., \& Falavigna, A. (2020). COVID-19 [recurso eletrônico]: Perguntas e Respostas Centro de Telemedicina da UCS. Caxias do Sul, RS: Educs. Recuperado em 12 de outubro de 2021 de: https://www.ucs.br/site/midia/arquivos/ebook-covid19-editora.pdf.

Ministério Da Economia. (2020). Panorama Macroeconômico: Conjunto amplo de dados sobre conjuntura, organizados pela SPE a partir de diversas fontes primárias de acesso público. Recuperado em 18 de junho de 2021 de: https://www.gov.br/fazenda/pt-br/centrais-deconteudos/publicacoes/conjuntura-economica/panorama-

macroeconomico/2020/panmacro spe slides -maio2020.pdf/view.

Zeng, N. Z., Zewen, L., Sherrianne, N., Dinggiang, C., \& Hongwei, Z. (2020). Epidemiology reveals mask wearing by the public is crucial for COVID-19 control. Medicine In Microecology, (4), 293-308, maio 2020. DOI: 10.1016/j.medmic.2020.100015. Recuperado em 27 de junho de 2021 de: https://www.sciencedirect.com/science/article/pii/S2468042720 $\underline{300117 .}$.

Osha. (2020). Occupational Safety And Health Administration. U. S. Department of Labor. Guidance on preparing workplaces for COVID-19. Recuperado em 21 de maio de 2021 de: https://www.osha.gov/Publications/OSHA3990.pdf.

Pará. (2020). Procuradoria Geral do Estado do Pará. Legislações Covid-19. Decreto no 800, de 31 de maio de 2020*. DOE $\mathrm{n}^{\circ}$ 34.495, de 18 de fevereiro de 2021. Recuperado de: http://www.pge.pa.gov.br/content/legislacoescovid19

Phan, T. L., \& Ching, C. T. (2019). A Reusable Mask for Coronavirus Disease 2019 (COVID19). Archives Of Medical Research, 51(5), 455-457. DOI: 10.1016/j.arcmed.2020.04.001. Recuperado em 27 de junho de 2021 de: https://www.sciencedirect.com/science/article/pii/S0188440920 303325.

Porsse, A. A., Souza, K. B. de, Carvalho, T. S., \& Vale, V. A. (2020). Impactos Econômicos do COVID-19 no Brasil. Nota Técnica NEDUR-UFPR N 01-2020, Núcleo de Estudos em Desenvolvimento Urbano e Regional (NEDUR) da Universidade Federal do Paraná, Curitiba, Abril/2020.

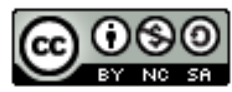



indústria de bebidas. O que mudou? Brazilian Journal of Production Engineering, 8(1), 33-48.

Rotondaro, R. G., Cristofoletti, I., \& Torres A. T. (2000). A informação sobre a satisfação do consumidor e seu papel na gestão da qualidade em empresas de alimentos. In: XX Encontro Nacional de Engenharia de Produção, São Paulo. Recuperado de: http://www.abepro.org.br/biblioteca/ENEGEP2000_E0204.PDF.

Silva, M. L., \& Silva, R. A. (2020). Economia brasileira pré, durante e pós-pandemia da Covid19: impactos e reflexões. Texto para discussão do Observatório Socioeconômico da Covid-19. Universidade Federal de Santa Maria (UFSM) - Rio Grande do Sul. Recuperado 15 de maio de 2021 de: https://www.ufsm.br/app/uploads/sites/820/2020/06/Textos-para-Discuss\%C3\%A3o07-Economia-Brasileira-Pr\%C3\%A9-Durante-e-P\%C3\%B3s-Pandemia.pdf.

Sousa, B. J. de., Paiva, J. M. de., \& Costa, T. M., (2020). COVID-19 e as Boas Práticas de Fabricação e manipulação de alimentos. Natal: UNI-RN, p. 67. Recuperado 28 de junho de 2021 de: https://redeabrasel.abrasel.com.br/upload/files/2020/08/XQM7hW6PyJq9NSJj12J5_03_3cd4 4e8b6fe4a77faa19dfa61af38428_file.pdf

Viana, F. L. E., (2021). Indústria de bebidas não alcoólicas. Fortaleza: Banco do Nordeste do Brasil, ano 6, n.175, jul. 2021. (Caderno Setorial, n.175). Recuperado em 13 de outubro de 2021 de: https://www.bnb.gov.br/s482-dspace/handle/123456789/905.

WHO. (2020). World Health Organization. Folha informativa sobre COVID-19. Recuperado em junho de 2021 de: https://www.paho.org/pt/brasil.

World Bank. (2020). Global Economic Prospects. Washington, DC: World Bank, JUNE 2020. DOI: 10.1596/978-1-4648-1553-9. License: Creative Commons Attribution CC BY 3.0 IGO. Recuperado em 30 de junho de 2020 de: https://openknowledge.worldbank.org/bitstream/handle/10986/33748/9781464815539.pdf. 